\title{
HACIA UNA TEORIZACIÓN DEL ABSURDO EN EL TEATRO DE MYRNA CASAS
}

\author{
POR \\ RAQUEL AGUILÚ DE MURPHY \\ Marquette University
}

Para la escritora puertorriqueña Myrna Casas ${ }^{1}$ la vida humana, la realidad cultural y todo su contexto socio-histórico son en definitiva material artístico. Es por ello que dedica su vida a la labor teatral, ya sea dirigiendo obras teatrales, enseñando el proceso de la actuación o escribiendo sus propias obras. En este sentido hay que considerarla como la única en su generación que desempeña consistentemente todas las funciones teatrales: dramaturga, profesora de arte dramático y directora teatral.

Myrna Casas comienza su carrera teatral durante la llamada "Generación del Sesenta" en Latinoamérica. Se inicia en el teatro con su obra Cristal roto en el tiempo (1960). En 1963 se sumerge en el mundo del absurdo para escribir su obra Absurdos en soledad. Con esta pieza dramática Myrna Casas viene a formar parte de un grupo de escritores latinoamericanos que intentan cambiar las formas, contenido y temas del teatro convencional. ${ }^{2}$ Este grupo de escritores, como por ejemplo, Iván García, Jorge Díaz, Griselda Gambaro, Antón Arrufat y Luis Rafael Sánchez, se preocupan no solamente en tratar de cambiar las

\footnotetext{
${ }^{1}$ Para una bibliografía de la autora véase: Josefina Rivera de Álvarez, Diccionario de la literatura puertorriqueña, Tomo I. (San Juan: Instituto de Cultura, 1970). La obra dramática de Myrna Casas se compone de las siguientes piezas teatrales: Cristal roto en el tiempo (1960), Absurdos en soledad (1963), La trampa (1964), Eugenia Victoria Herrera (1964), El impromptu de San Juan (sf.), Tres (1974), No todas lo tienen, y Cuarenta años después (1975).

2 Entiéndase por teatro convencional aquél cuyos elementos (personajes, vestuario, escenografia, mobiliario, etc.) son reales, o sea que procuran re-presentar una realidad mimética, y la trama se desarrolla siguiendo los principios de exposición, punto culminante y descenlace. Edward A. Wright define el movimiento dramático convencional de la siguiente forma:

The third aspect of the playwright's form is the structure or building of his play. There are certain specific materials that every play must possess. They are generally called the exposition, the inciting moment, the rising action, the turning point, the falling action, the climax, and the conclusion. Each has its place in the structure of a play.
}

Understanding Today's Theatre (Prentice Hall, 1959) 50-51. 
formas o maneras de expresión teatral tradicionales del "realismo", sino que también procederán a incorporar temas de mayor vigencia y compromiso histórico, social y político. Sus obras dramáticas van a reflejar una angustia existencial y la soledad individual como resultado de la mecanización, los horrores producidos por la Segunda Guerra Mundial y la deshumanización del ser humano como causa y efecto del materialismo burgués, la falta de comunicación y la erradicación de la individualidad.

En 1964 Myrna Casas publica otra obra teatral, La trampa. ${ }^{3}$ En esta obra expone las incongruencias de un mundo que se niega a establecer todo tipo de comunicación humana. Esa falta de comunicación, a su vez, produce la alienación y la soledad. En el presente trabajo me propongo examinar cómo La trampa no es simplemente la representación de la incomunicación como tema paradigmático del Teatro del Absurdo; Myrna Casas no sólo registra en esta obra su interpretación del absurdo sino que asimila y utiliza sus técnicas.

En La trampa nos enfrentamos a unos personajes que muestran la agonía y desesperación de vivir dentro de una realidad ficticia que los va acorralando, los atrapa y les impide ser ellos mismos. Este sentido de angustia metafísica producida por lo absurdo de su condición humana y conducente a la soledad es el tema que prevalece a lo largo de toda la obra. Desde la primera escena del drama Myrna Casas nos enfrenta al dilema existencial de una pareja matrimonial.

La trampa. Breve tragicomedia en dos actos indivisibles., nos enfrenta a una serie de situaciones absurdas del matrimonio de Juan y Nena. En el primer acto, "El compromiso", Juan viene a la casa de Nena para pedir a los padres de ésta su mano en casamiento. Luego de una discusión trivial y sin sentido con los padres de Nena, Juan se compromete con ella y como consecuencia cae en la "trampa" en que ha vivido durante años Papito, su futuro suegro. En el segundo acto, "El matrimonio", aparecen Juan y Nena, ya casados y viviendo en un ambiente de aburrimiento y desilusión provocados en ellos por la imposición social de la institución matrimonial. Como resultado, Juan y Nena inventan a otros personajes (el otro, la otra) y establecen nuevas relaciones que les permiten eliminar el aburrimiento y el rechazo que sienten el uno por el otro. De esta forma se integran al ciclo anteriormente establecido por Papito y Mamá. Juan y Nena vienen a representar, en la continuación cíclica, el estado de enajenación al que han sido sometidos el hombre y la mujer en el matrimonio, hasta el punto de convertirlos en víctimas de las instituciones y convencionalismos sociales. Esta enajenación y sobre todo la imposición social a la que están sometidos se revelan claramente en el siguiente diálogo:

Juan: -¡Dios mío! No puedo más. (A Nena) Quisiera hablar con tu padre. Nena: - ¿Para qué?

'Myrna Casas, La trampa (Madrid: Biblioteca de autores de Puerto Rico, 1987). Todas las citas provienen de esta edición. 


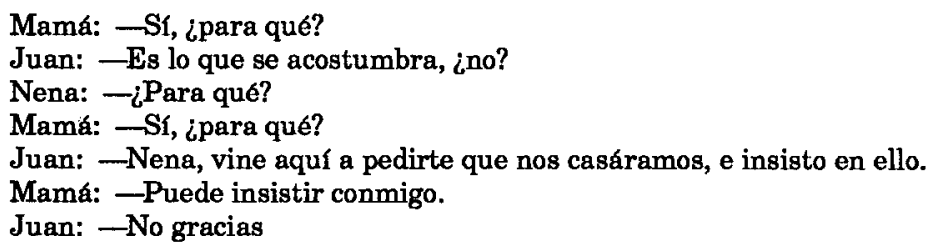

Juan: -Me gustaría hablar con tu padre sobre ello. Es lo que ...

Mamá: -Acostumbra (78-79).

Juan y Nena se ven obligados a seguir las fórmulas del comportamiento social aprendido e impuesto por sus padres y por la sociedad. Sin embargo, es esa imposición social la que no les permite mostrar sus sentimientos y preocupaciones y dar rienda suelta a sus verdaderas emociones e identidades. Tanto Nena como Juan se ven obligados a ponerse la máscara social que imponen las costumbres y la tradición. Estos convencionalismos sociales carentes de significación auténtica son los que llevan a estos personajes a caer en la "trampa" cíclica del matrimonio.

Myrna Casas lleva a la escena, por medio de la representación del absurdo del matrimonio, la represión impuesta por una serie de condiciones sociales y culturales que no le permiten desarrollar y manifestar a la pareja su ser "auténtico". Para mostrar esta condición enajenante del ser humano, Casas utiliza técnicas del teatro del absurdo que le ayudan a proyectar en la escena la desorientación mental y emocional de los personajes mostrando un escenario en donde la realidad no puede ser transmitida racionalmente. Veamos.

Una característica absurda planteada por Casas en esta obra es la incapacidad de comunicar del lenguaje. ${ }^{4}$ El lenguaje de sus personajes nos muestra al ser humano como un ente incapaz de actuar para transformar la realidad en que vive. Nos muestra a unos personajes sumidos en la repetición esquemática de un comportamiento dado impuesto desde afuera.

El lenguaje de La trampa representa claramente las incongruencias, angustias y obsesiones de los personajes. Éstos hablan en la escena, dialogan, pero lo que uno dice lo entiende el otro en forma totalmente distinta. A pesar de que están hablando no se establece entre ellos un intercambio de ideas; no logran realizar ningún tipo de intimidad y mucho menos de comunicación. El

4 Martin Esslin define al lenguaje del teatro del absurdo de la siguiente forma:

El teatro del absurdo ha recobrado la libertad de emplear el lenguaje como un mero componente $\rightarrow$ veces dominante, a veces secundario - de sus multidimensionales imágenes poéticas. Al poner el lenguaje de la escena en contraste con la acción, al reducirlo a una charla discursiva por la lógica poética de la asociación o la asonancia, el teatro del absurdo ha abierto una nueva dimensión a la escena. Por su devaluación del lenguaje [...] está a tono con las tendencias de nuestro tiempo.

El teatro del absurdo, Traducción de Manuel Herrero (Barcelona: Editorial Seix Barral, 1966) 307 . 
lenguaje es fórmula y variedad, por lo tanto esquemático y generalizador. Los signos se han ido vaciando de significado vital hasta llegar a convertirse en puros clichés, signos carentes de significación. La conversación que se produce entre los personajes es automática, y se crea así un diálogo sin sentido, que en su formato es telegráfico. Mustra este punto el siguiente diálogo:

Juan: - Señor, tengo el honor de pedir a usted la mano de su hija.

Papito: - (Señala a MAMÁ y a NENA) ¿por qué no se lleva a las dos?

Juan: -No, a una sola.

Papito: -Las dos gratis, vamos.

Juan: -Lo siento.

Papito: -ipor quién?

Juan: -No ... no sé.

Papito: -Entonces ¿por que dice que lo siente?

Juan: -Le digo que no sé.

Papito: $-i$ Me tiene pena?

Juan: -No, no a usted.

Papito: - ¿Por qué no?

Juan: -Pues ... yo ... ¿debra tenerle?

Papito: -iTener qué?

Juan: -Pena por usted.

Papito: -Ve, me tiene pena. ¿Por qué dijo que no la tenía?

Juan: -No la tengo. Quiero decir ... teńa, quiero decir que le tengo (82-83).

Como podemos observar aquí, la lengua se ha convertido en una barrera más que interrumpe la comunicación. Cada personaje emplea el lenguaje para sus propios fines, sin un lógicointercambio dialéctico de ideas en la conversación cotidiana. La falta de un tema vital y significativo impregna a la obra, en general, de abundantes frases y conversaciones triviales que destruyen todo el concepto que se podría tener de estos personajes como seres humanos reales y vitales. Al perder su significado real, estos personajes se nos presentan en la obra como seres reprimidos, carentes de personalidad y de identidad. Son seres que vienen a representar amargas caricaturas de la vida y del hombre, despojados de sus circunstancias sociales e históricas; es decir, se concretiza en éstos el personaje dramático del teatro del absurdo.

En La trampa nos enfrentamos a una serie de personajes ${ }^{5}$ representativos de una sociedad incomprensible, de seres marginados y aplastados en su

${ }^{5} \mathrm{Al}$ referirse al personaje dentro del teatro del absurdo, George Woodyard lo define de la siguiente forma:

For greater intensity, the dramatists often limit themselves to two-character plays, a technique which permits closer examination, not of motivation and psychological development, but of irrationality of the frustrated and desperate human animal - anti-heroes instead of the traditional heroic figures. Feelings of contempt, insult, and hatred lead to physical violence; interpersonal relationships are brutally shattered. Fragmentation occurs in many areas.

En "The Theater of the Absurd in Spanish America". Comparative Drama 3(1969) 186. 
contexto social deshumanizado, como en el Teatro del Absurdo. Por ejemplo, el hombre en la obra asume una posición pasiva. Juan representa al ser alienado, muñeco de la sociedad. En vez de enfrentarse a su propio "yo" y rebelarse contra el mundo que lo mantiene, opta por aceptar su destino final sin rebelarse. Le teme a la vida y también a la rebelión, en este caso particular, la de las mujeres. Se encuentra en una "trampa" de la que quiere escapar, pero no tiene el valor ni la voluntad de enfrentarse a esa realidad y librarse de ella. El siguiente diálogo entre los personajes masculinos de la obra demuestra este punto:

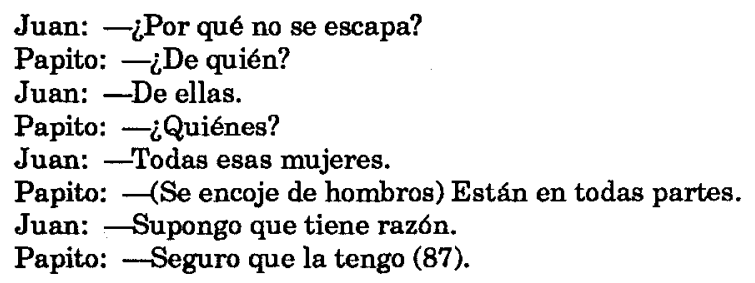

Estos hombres, tanto Juan como Papito, tienen miedo de cambiar su situación presente. Ellos temen, además, afrontar al mundo exterior. Sienten miedo, un miedo incontrolable que los convierte en prisioneros de su propia realidad. Como consecuencia viven en su propio mundo, encerrados "en una lata de aluminio" (79), creando realidades ilusorias y evadiendo su existencia trágica y absurda. Así los hombres en esta obra de Myrna Casas son personajes caricaturizados que muestran rasgos grotescos y típicos del personaje masculino del teatro del absurdo. Aún más, son especies de títeres manipulados y controlados por los antojos de una sociedad burguesa en decadencia.

Por otro lado, la mujer es representación de un ser marginado que lucha arduamente por conservar su posición dentro de una sociedad machista. Ellas procuran revelarse. Por ejemplo, Nena se opone a la institución matrimonial que la ha mantenido esclavizada. Está descontenta con la vida matrimonial y la sociedad burguesa-machista. Por consiguiente está presta a pelear para escapar de esa realidad que la oprime; está dispuesta al cambio. El aburrimiento y encarcelamiento que experimenta en el matrimonio la hacen finalmente asumir una posición combatiente y en busca de unalibertad soñada. Finalmente encuentra la fuerza moral y la voluntad de enfrentarse a ese mundo de libertad que le abre las puertas a lo nuevo, a algo mejor:

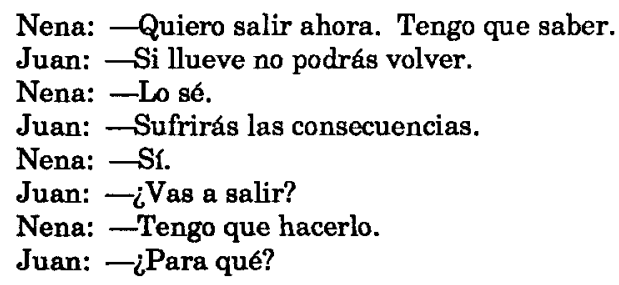




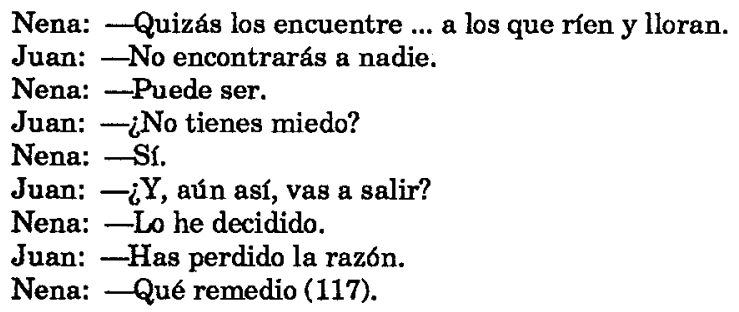

Por medio de este diálogo podemos observar cómo Nena adquiere conciencia de la realidad circundante. Deja de actuar y comportarse de acuerdo a los cánones tradicionales que la sociedad machista-burguesa le ha impuesto a la mujer. Logra, al fin, encontrarse a sí misma y esto la lleva consecuentemente a rechazar seguir viviendo con el "esposo". Así, rechaza desafiante y conscientemente la institución social y marginante del matrimonio y sale al mundo exterior en busca de su propia libertad y autenticidad. En este sentido Nena no es representativa del personaje del absurdo que vive atrapado dentro de su propia realidad y de la cual no encuentra escape. Ella tiene la posiblidad de escapar de ese mundo agónico en que se encuentra atrapada. Con Nena podemos ver cómo Myrna Casas altera e interpreta el teatro del absurdo, pues en esta obra ella asume una postura feminista radical y nos presenta a la mujer asumiendo una postura de ruptura total contra los cánones que se dan en la sociedad moderna. Dentro del teatro del absurdo los personajes no logran escapar de ese mundo caótico y decadente en que viven atrapados; sin embargo, en esta obra la mujer asume una posición de crítica social y llega a la redefinición de su puesto en la sociedad machista-burguesa.

El humor, otra característica del absurdo, es otro recurso utilizado por Casas en esta obra dramática para representar el absurdo en la vida de los personajes. La función del humor en este tipo de teatro es dar una visión crítica del mundo para distanciarnos de una condición existencial caótica e incomprensible. ${ }^{6}$

El aspecto cómico en La trampa no sólo se desprende de las situaciones dramáticas en sí, sino de la mezcla de personajes, situaciones, actuación,

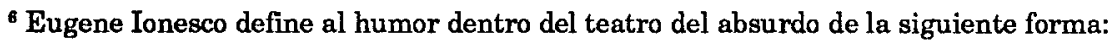
El humor permite [...] una vision crítica del mundo, ayuda a desprendernos y alejarnos, en cierto modo, de nuestra condición humana tragi-cómica, del malestar de la existencia, luego de haberlos conocido y superado.

Más adelante comenta que lo cómico es una expresión de lo novedoso que nace en lo cotidiano de la acción, siempre que se la lleve más allá de sus límites: sentir lo absurdo de lo cotidiano y del lenguaje, su inverosimilitud, ya significa haberlo sobrepasado; primeramente, es preciso hundirse en él. Lo cómico es lo insólito trivial: lo suprarreal está allí al alcance de nuestras manos, en la charlatanería de todos los días".

"La Démitification par l'humoir noir", citado por Marta Glukman en Eugene Ionesco y su teatro (Chile: Editorial Universitaria, S.A., 1965) 137, 141. 
lenguaje y recursos escénicos que dan un efecto cómico a la obra. Por ejemplo, el teatro del absurdo nos presenta unos personajes que actúan como máquinas o marionetas. El estado de automatismo y la mecanización de los personajes carentes de sentimientos humanos, suscitan la risa del espectador. Esa risa surge cuando vemos actuar como muñecos a unos personajes que tienen la apariencia de seres humanos.

EnLa trampa, Papito es el personaje que mejor representa este automatismo con el propósito de causar risa. Este es un ser marginadoy dominado por Mamá. Cuando aparece en escena adquiere la forma de una materia inanimada que se mueve mecánicamente por medio de hilos y resortes, como si fuera una marioneta:

Papito sale de la lata. Tiene medio siglo de algo y mejor cuerpo que Mamá. Papito: -(Canta una tonada de "Happy Birthday".)

Mamá: - Callate! Cumpleaños feliz ... Cumpleaños feliz ... Te deseamos ...

Papito: -(Empieza a llorar.) Le acompaño en su sentimiento.

Mamá: - Callate! No es el cumpleaños de nadie, ni se ha muerto nadie.

Papito: - iPor qué me sacaron, entonces?

Mamá: - Tenemos un problema.

Papito: - Prefiero cantar. (Empieza a cantar “Cumpleaños feliz"... (80).

La risa resultante de este diálogo es causada por el efecto del mecanismo, automatización y rigidez de Papito, que no trata de establecer comunicación alguna con el mundo exterior ni con los que lo rodean. ${ }^{7}$ Papito refleja aquí un cierto grado de automatismo que no le permite enfrentarse a la realidad de su diario vivir. En el momento en que la situación requiere su atención, asume una posición risible y hasta cierto modo infantilista. ${ }^{8}$ Pretende actuar como adulto pero, en el fondo, no es más que un simple niño disfrazado de adulto. Sus actuaciones, gestos y hasta su lenguaje son en sí una manifestación de su inmadurez y de su incapacidad de actuar como hombre adulto. Aunque la risa

\footnotetext{
${ }^{7}$ Sobre este particular Bergson manifiesta lo siguiente: 'Es comico el personaje que sigue automáticamente su camino, sin cuidarse de establecer contacto con los demás". Henri Bergson, La risa. Traducción de María Luisa Pérez Torres (Madrid: Espasa Calpe S.A., 1969) 112.

8 Un aspecto muy importante en el surgimiento de la risa es aquél que Freud llama "renacimiento de lo infantil". Nos reímos ante una situación, una forma de expresión verbal, o un gesto del personaje cuando vemos en alguna de estas formas una manifestación del carácter infantil del ser humano:

La risa surgirá [...] de la comparación entre el yo del adulto y el yo considerado como niño. La misma dualidad del sentido de la diferencia cómica, en la que tan pronto el exceso como el defecto del gesto nos resultan cómicos, se halla de acuerdo con las condiciones infantiles, pues en uno y otro caso la comicidad surge siempre del lado en que aparece lo infantil".
}

El chiste y su relación con lo inconsciente. Traducido por Luis López Ballesteros de Torres (Madrid: Alianza Editorial, 1970) 50. 
provocada por él en el espectador es momentánea, esa risa es el reconocimiento en el espectador de una conducta ridícula y absurda. De ahí que Casas, al utilizar la crítica que surge de lo cómico, haga uso de otra característica del Teatro del Absurdo.

Como hemos visto, Myrna Casas utiliza en La trampa una serie de recursos técnicos y teorias características del Teatro del Absurdo. Mediante su uso del lenguaje, de las situaciones dramáticas y de las técnicas teatrales, lleva a escena la condición degradante y enajenante del hombre y de la mujer en una sociedad que ha perdido su razón de ser. En este sentido su obra, La trampa, ha logrado mantenerse dentro de los preceptos del Teatro del Absurdo en general.

En La trampa, Casas nos muestra cómo el lenguaje, la sociedad, los patrones de conducta aprendidos y la mecanización del mundo han encerrado al individuo y cerrado sus fronteras, impidiendo de esa forma su desarrollo intelectual y humano. Sin embargo, no encontramos en esta obra una filosofía totalmente pesimista y de derrota total como en el Teatro del Absurdo europeo. Al final de la obra se mantiene una puerta abierta, una posible salida de la situación que tiene prisioneros a los personajes. Es el personaje de Nena el que mantiene una ilusión: la esperanza de que el ser humano logre, en un futuro cercano, crear conciencia de sus valores auténticos y de la necesidad de producir un cambio hacia un futuro "mejor".

Para concluir, sería importante señalar que una de las diferencias fundamentales entre el teatro latinoamericano del absurdo y el teatro europeo es que los escritores europeos miran a la realidad circundante como un círculo cerrado en donde no hay ninguna posiblidad de escape. Por el contrario, el escritor hispanoamericano, y este sería el caso de Myrna Casas con el desenlace abierto, ve que esa realidad absurda y caótica que aprisiona no representa un estado permanente sin salida. Desde esta perspectiva, Myrna Casas se coloca en esa interpretación latinoamericana del absurdo al hacer posible que Nena escape de ese mundo agónico en que vivió. De este modo, como escritora latinoamericana, Casas se encuentra mucho más comprometida que los autores europeos con la realidad socio-política y con la posibilidad de cambio, y así deja en su producción dramática una puerta abierta a un futuro donde no hay cabida a callejones sin salida. 